\title{
Special issue: Sustainable consumption and production in emerging economies
}

Sustainable production and consumption is a major challenge for emerging economies, especially in fast-growing regions such as the BRIC countries (Brazil, Russia, India, and China). Sharing knowledge and best practice as well as barriers and opportunities for addressing these challenges is particularly important in the search for sustainability in emerging economies.

This special issue represents an attempt in this direction, providing research findings on different sustainable production and consumption challenges in emerging economies such as Ghana, India, Indonesia and China. The six highly multidisciplinary papers included in this issue cover activities as diverse as cocoa farming, palm oil production, provision of sanitation and car manufacture, and topics such as corporate sustainability reporting and green supply chain management.

For example, the paper by Peprah examines the factors that affect the livelihoods of cocoa farmers in Ghana. The country is the second largest producer of cocoa globally and the industry supports the livelihoods of $26 \%$ of the population. However, the results of the study indicate that cocoa farmers live in poverty, with inadequate access to food, housing and health care, depending heavily on loans to make ends meet. They are also made vulnerable by land degradation, corruption in internal cocoa marketing and inflation. Furthermore, their livelihoods are facing threats from the newly found oil and the ongoing restructuring of the economy to make it more industry and service oriented rather than dependent on agriculture.

Moreno-Peñaranda et al. consider palm oil in Indonesia, analysing the perceptions on the barriers for improving its sustainability, as held by different stakeholder groups. The results show that the perceptions are highly divergent among the stakeholders and most polarised for two environmental impacts: greenhouse gas emissions and biodiversity loss. However, the study identified an underlying optimism among some stakeholders, including local communities, about the feasibility of a 'technical fix' for improving the sustainability of palm oil production.

Focusing on sanitation, Ganesapillai et al. show how agricultural waste such as coconut shells can be utilised to recover nutrients from human urine to be used in agriculture. This has a two-fold advantage: it reduces health risks by diverting urine from water systems, especially in countries which lack adequate sanitation, while recycling nutrients back into food systems and avoiding the need for artificial fertilisers. Thus, this and other closed-loop sanitation methods could play an important role in improving the sustainability of agriculture, particularly in emerging economies.

Pallaro et al. provide a review of previous studies on sustainable production and consumption in the automotive sector. The analysis indicates that most authors have focused on the production rather than consumption stage and have mainly evaluated the economic and environmental aspects with little or no consideration given to the social dimension of sustainability. The majority of the papers discuss sustainability issues in the context of developed countries. However, there has been a growing interest in the topic in some emerging nations, such as China. The authors suggest future research directions that could be helpful for the automotive sector in developing long-term sustainable business models.

Kumar et al. broaden the discussion from a single sector to consider companies in India across 10 different sectors, comparing their sustainability reports. Using the Global Reporting Initiative (GRI) as a standard, the reports are compared on the content with respect to the economic, environmental and social dimensions of sustainability as well as the stakeholder groups addressed by the reports. The results of the analysis show that there was little difference in the content of the reports with respect to the sustainability dimensions, with the main distinguishing factor being the stakeholders that the reports were aimed at. Consumers and suppliers were found to be the most targeted groups across different companies and sectors.

Also focusing on India, Dubey et al. identify enablers for adoption of green supply chain management (GSCM) practices. These include top management commitment, institutional pressures, supplier and customer relationship management of financial and environmental performance. The study highlights that manufacturing firms that adopt GSCM practices enjoy benefits in terms of improved business and environmental performance.

Editor of the Special Issue Charbel José Chiappetta Jabbour UNESP - Universidade Estadual Paulista (Sao Paulo State University), Av. Engenheiro Edmundo Carrijo Coube, 14-01, Bauru-SP, 17033-360, Brazil E-mail addresses: prof.charbel@gmail.com, abjabbour@feb.unesp.br. 